\title{
Patterns and clinical outcomes of injuries related to two-wheeled vehicles (bicycle and motorcycle) in the geriatric population: a nationwide analysis in South Korea (2016-2018)
}

Yoonhyung Choi ${ }^{1}$, Duk Hee Lee ${ }^{1 *+}$ and Jung II Lee 2*+ $^{*+1}$

\begin{abstract}
Background: South Korea has a rapidly ageing population. This study aimed to provide epidemiologic data and to identify the characteristics of the patterns and clinical outcomes of two-wheeled vehicle-related injuries (bicycle and motorcycle) in elderly riders.

Methods: This study retrospectively analyzed data from the National Emergency Department Information System from 2016 to 2018. Adult patients ( $\geq 20$ years old) who were injured while using two-wheeled vehicles were included. Elderly patients were defined as being 65 years and older. The analysis was performed for 65,648 bicyclerelated injuries (15,272 elderly patients) and 87,855 motorcycles-related injuries (17,292 elderly patients).

Results: In emergency departments (EDS), the average injury severity score (ISS) for motorcycle-related accidents was $9.8 \pm 11.2$ in the younger group and $14.1 \pm 14.7$ in the elderly group $(p=0.001)$. In addition, the average ISS of bicycle-related accidents was $7.1 \pm 8.9$ in the younger group and $10.5 \pm 12.3$ in the elderly group $(p=0.001)$. Twowheeled vehicle accident mortality rates of elderly riders ( $0.9 \%$ for bicycle and $1.8 \%$ for motorcycle in the ED; $4.1 \%$ for bicycle and 3.8\% for motorcycle in the hospital) were more than twice those of younger riders.

The elderly stayed in the hospital longer than younger patients $(485.2 \pm 543.0 \mathrm{~h}$ vs $336.8 \pm 385.5 \mathrm{~h}, p=0.001)$ for bicycle-related injuries. They also stayed longer for motorcycle-related injuries $(529 \pm 598.6 \mathrm{~h}$ vs $452.0 \pm 543.55 \mathrm{~h}, p=$ 0.001 ).

The logistic regression analysis showed that age $\geq 65$ years was an independent factor associated with severe trauma (ISS $\geq 16$ ) for both bicycle-related injuries (adjusted odds ratio [OR] 2.185 [95\% Confidence Interval (CI) 2.072-2.303]) and motorcycle-related injuries (adjusted OR 1.220 [95\% Cl 1.137-1.287]).
\end{abstract}

\footnotetext{
*Correspondence: ewhain78@gmail.com; osjungil@gmail.com

${ }^{\dagger}$ Duk Hee Lee and Jung II Lee contributed equally as corresponding authors

to this work.

'Department of Emergency Medicine, College of Medicine, Ewha Womans

University, Seoul, South Korea

${ }^{2}$ Department of Orthopedic Surgery, Korea University Guro Hospital, Seoul,

South Korea
}

(c) The Author(s). 2021 Open Access This article is licensed under a Creative Commons Attribution 4.0 International License, which permits use, sharing, adaptation, distribution and reproduction in any medium or format, as long as you give appropriate credit to the original author(s) and the source, provide a link to the Creative Commons licence, and indicate if changes were made. The images or other third party material in this article are included in the article's Creative Commons licence, unless indicated otherwise in a credit line to the material. If material is not included in the article's Creative Commons licence and your intended use is not permitted by statutory regulation or exceeds the permitted use, you will need to obtain permission directly from the copyright holder. To view a copy of this licence, visit http://creativecommons.org/licenses/by/4.0/ The Creative Commons Public Domain Dedication waiver (http://creativecommons.org/publicdomain/zero/1.0/) applies to the data made available in this article, unless otherwise stated in a credit line to the data. 
Conclusion: Two-wheeled vehicle-related injuries in the elderly were associated with higher ISS, length of hospital stay, and mortality than in younger riders. Analysing the characteristics of two-wheeled vehicle-related injuries in the elderly can be the basis for planning to reduce and prevent injuries in elderly riders.

Keywords: Bicycle, Motorcycle, Two-wheeled vehicle, Injury pattern, Injury severity score, Geriatric trauma

\section{Background}

Bicycles and motorcycles are important and affordable transportation devices. The use of bicycles for urban transportation and leisure activity and of motorcycles for transportation and on-demand delivery is increasing. Approximately 800 million people worldwide use bicycles as a means of transportation [1-3]. Bicycles offer many advantages by promoting an interest in health and participation in leisure activities, lowering fuel-related air pollution, and reducing traffic caused by automobiles. Therefore, countries such as the Netherlands, Denmark, the United States, and Germany have implemented policies to encourage bicycle use [4-6]. In South Korea, the Act on Activation of Bicycle Use, enacted in 1995, has been amended more than 10 times, and by enacting enforcement decrees and regulations, efforts to further encourage bicycle use and reduce the risk of accidents are ongoing. However, the definition of bicycle roads is still unclear in South Korea, compared with the aforementioned countries, resulting in a combination of bicyclepedestrian roads and bicycle-car roads. There are no rules pertaining to bicycle safety equipment (such as bicycle bells) and no traffic signs for bicycles. Bike crossings must also be made more secure $[7,8]$. The rate of bicycle use is increasing owing to the government policy on the promotion and convenience of bicycle use $[9,10]$. According to the National Statistical Office, each household in South Korea owns 1.6 bicycles, and one-third of the population uses bicycles [11]. Meanwhile, as the usage rate increses, the number of bicycle accidents does as well. According to Korea Road Traffic Authority data, there were 12,000-17,000 bicycle accidents per year from 2011 to 2015. Although there was a slight decrease in 2016 and 2017, the number of deaths was approximately 250 per year from 2011 to 2017. The data also show that the proportion of bicycle accident deaths gradually increased over the course of 7 years, from 5.3 to $6.3 \%$ [12].

The fatality rates of motorcycle accidents were higher than those of other means of transportation due to the limited safety precautions and the difference in the mechanism of injury [13]. Studies have shown that age, helmet use, alcohol consumption, speed, road surface condition, road safety barriers, engine displacement, collision objects, and weather affect the severity of motorcycle accidents [14-17]. The severity and mortality rate of traffic accidents vary significantly from country to country because they are affected by the unique topography and transportation system of each country and the vehicle type used. As of 2015, South Korea ranked second highest in traffic accidents among member countries of the Organisation for Economic Co-operation and Development with 455 traffic accidents per 100,000 population and fourth in traffic accident deaths with 9.1 per 100,000 population [18]. Road traffic-related crashes are the leading cause of injuries requiring hospitalization, and bicyclists and motorcyclists contribute to the morbidity and mortality rates of road crash casualties [19]. The fatality rates of traffic accidents while riding a motorcycle or walking are higher in South Korea than in other countries [20].

In 2018, $14.4 \%$ of the total population of South Korea was $\geq 65$ years old. This proportion is expected to increse to $20.3 \%$ in 2025 and $46.5 \%$ in 2067 [21]. Moreover, there is increasing number of elderly cyclists and motorcyclists, and this trend is expected to continue. Elderly riders may have more risk factors and problems associated with cycling as they may have decreased peripheral vision, coordination, balance, and cognitive function [22]. However, there have been no studies using data from emergency departments (EDs) and hospitals in a nationwide database to compare the different characteristics of two-wheeled vehicle-related injuries in older and younger riders.

Understanding such differences, including their incidence and type, could contribute significantly to establishing safety policies. Hence, this study aimed to provide epidemiologic data and to identify characteristics of the patterns and clinical outcomes of two-wheeled vehicle-related (bicycle and motorcycle) injuries in elderly riders.

\section{Methods}

\section{Setting and data collection}

This retrospective study used the data collected from the National Emergency Department Information System (NEDIS) from January 2016 to December 2018. NEDIS transmits data to the National Emergency Medical Centre's server operated under the supervision of the Korean Ministry of Health and Welfare. Patient information is transferred automatically in real time from all South Korean EDs nationwide. To revitalize the use of emergency medical information, the Korean Ministry of Health and Welfare established the NEDIS database in 2001. This information 
is qualified as accurate, and the results are reported by the Ministry of Health and Welfare on an annual basis.

There are 36 regional emergency medical centres (Level 1), 117 local emergency medical centres (Level 2), and 119 local emergency medical rooms (Level 3) in South Korea. Between 2016 and 2018, 399 out of 401 emergency medical institutions participated in NEDIS data collection [23].

\section{Variables and outcome measures}

NEDIS collects demographic and clinical data: age, sex, ED visit date, ED visit time, geographic location of $E D$, insurance type, helmet use, means of visit, consciousness of patients in the ED (alert mental state and altered mental state, including verbal responses, pain responses, and unresponsiveness), systolic blood pressure, diastolic blood pressure, pulse rate, respiratory rate, diagnosis in the ED, injury severity score (ISS), and disposition after ED care (discharge, transfer to another hospital, admission to general ward $[\mathrm{GW}]$ or intensive care unit [ICU]). For admitted patients, the final diagnosis data and medical results on discharge were considered for the study. We divided ED visit dates by season: spring (March to May), summer (June to August), autumn (September to November), and winter (December to February). The time of the visit was divided into dawn (00:00 to $05: 59 \mathrm{~h})$, morning (06:00 to $11: 59 \mathrm{~h}$ ), afternoon (12:00 to $17: 59 \mathrm{~h})$, and night (18:00 to $23: 59 \mathrm{~h})$.

Injured patients aged $\geq 20$ years old were included, and we defined the elderly as patients aged $\geq 65$ years. Urban areas included eight cities and their metropolitan areas, and rural areas included seven provinces and Jeju Island.

During the study period, there were 212,112 twowheeled vehicle-related injuries. In South Korea, drivers' licenses are issued to adults aged $\geq 20$ years; therefore, patients under 19 were excluded. A total of 4267 patients with missing or incomplete data were excluded.
The younger group under 65 years of age and the elderly group aged 65 and older were compared. The final analysis was performed on 65,648 bicycles-related injuries $(15,272$ elderly patients) and 87,855 motorcycles-related injuries (17,292 elderly patients). Figure 1 shows the study flow chart for enrolled patients. We analysed the final diagnosis to categorise the injury (injury regions and fracture sites) according to the International Classification of Diseases, Tenth Revision [24]. ED disposition, duration of hospitalisation, and mortality were analysed to determine the clinical outcomes in both younger and elderly riders.

\section{Statistical analysis}

We analysed and compared the variables of the patients and injury-related characteristics between the younger and elderly groups. Categorical variables were analysed with the chi-square test, and Student's $t$-test was used for continuous variables. Gender, season of injury, time of injury, helmet use, age group (younger and elderly), and area (urban or rural) showed significant differences between ISS $\leq 15$ and ISS $\geq 16$ in the univariate analysis. To investigate the factors predicting severe trauma (ISS $\geq 16$ ), a multivariable logistic regression analysis was performed using these factors for each bicycle and motorcycle group. A two-tailed $p$-value of $<0.05$ was considered statistically significant. The Statistical Package for the Social Sciences Statistics for Windows, version 21 (International Business Machines Corporation, Armonk, NY, USA) was used for the analysis.

\section{Results}

Incidence of Korean traffic accidents and two-wheeled vehicle-related (bicycle and motorcycle) related injuries (Table 1)

The annual total incidence of patients with traffic injuries admitted to EDs showed an increasing trend from

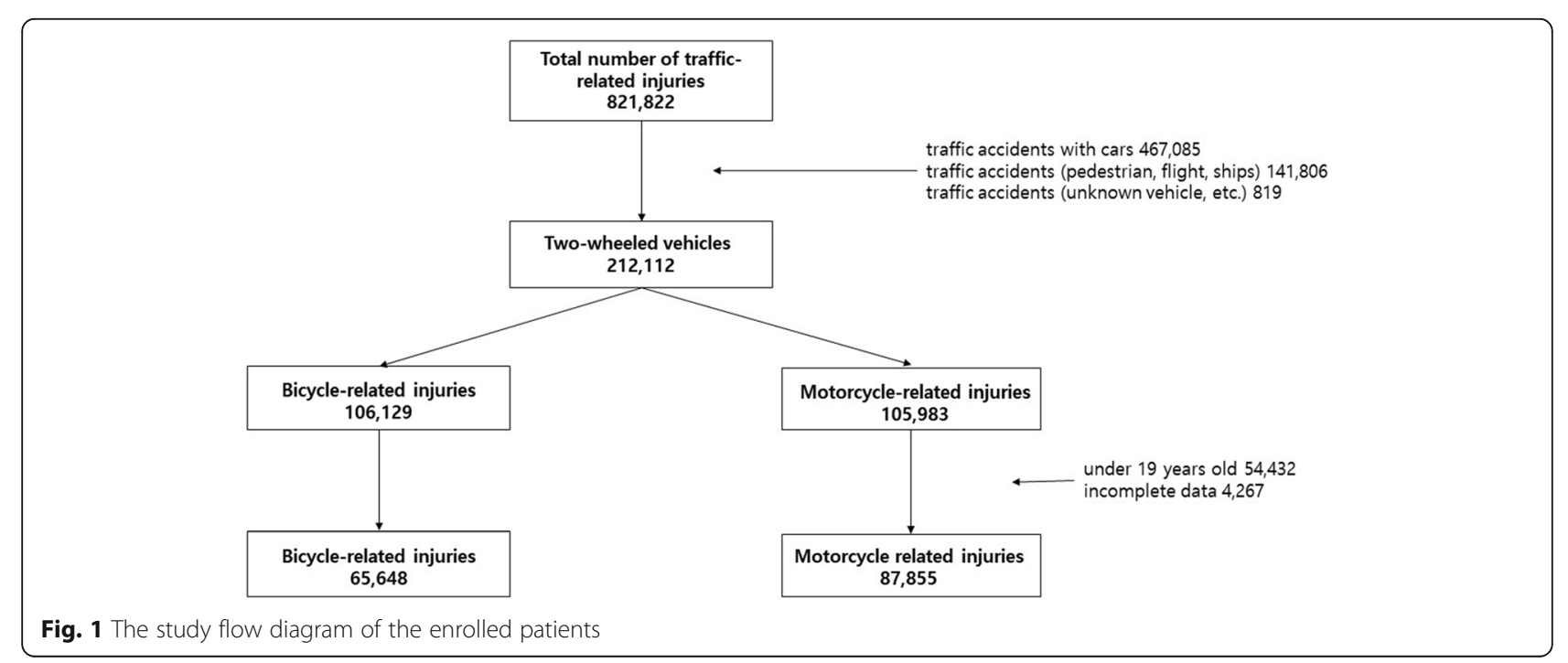


Table 1 Incidence of Korean traffic accidents and two-wheeled vehicle-related (bicycle and motorcycle) related injuries in the emergency department (2016-2018)

\begin{tabular}{|c|c|c|c|c|c|c|c|c|c|}
\hline \multirow{3}{*}{$\begin{array}{l}\text { Korean } \\
\text { population by } \\
\text { age }\end{array}$} & \multirow[b]{2}{*}{ Younger } & \multicolumn{2}{|l|}{2016} & \multicolumn{2}{|l|}{2017} & \multicolumn{2}{|l|}{2018} & \multicolumn{2}{|l|}{ Total } \\
\hline & & \multicolumn{2}{|l|}{$34,653,358$} & \multicolumn{2}{|l|}{$34,682,815$} & \multicolumn{2}{|l|}{$34,741,436$} & \multicolumn{2}{|l|}{$104,077,609$} \\
\hline & Elderly & \multicolumn{2}{|l|}{$6,995,652$} & \multicolumn{2}{|l|}{$7,356,106$} & \multicolumn{2}{|l|}{$7,650,408$} & \multicolumn{2}{|l|}{$22,002,166$} \\
\hline & & incidence & $\begin{array}{l}\text { Number of } \\
\text { injuries } / 100,000 \\
\text { population }\end{array}$ & incidence & $\begin{array}{l}\text { number of } \\
\text { injuries } / 100,000 \\
\text { population }\end{array}$ & incidence & $\begin{array}{l}\text { number of } \\
\text { injuries } / 100,000 \\
\text { population }\end{array}$ & incidence & $\begin{array}{l}\text { number of } \\
\text { injuries/100,000 } \\
\text { population }\end{array}$ \\
\hline \multirow{2}{*}{$\begin{array}{l}\text { Total traffic } \\
\text { injuries }\end{array}$} & Younger & 186,803 & 539.1 & 192,764 & 555.8 & 189,479 & 545.4 & 569,046 & 546.8 \\
\hline & Elderly & 35,462 & 506.9 & 40,524 & 550.9 & 40,924 & 534.9 & 116,910 & 531.4 \\
\hline \multirow{2}{*}{$\begin{array}{l}\text { Bicycle-related } \\
\text { injuries }\end{array}$} & Younger & 17,362 & 50.1 & 17,347 & 50.0 & 15,667 & 45.1 & 50,376 & 48.4 \\
\hline & Elderly & 4664 & 66.7 & 5347 & 72.7 & 5262 & 68.8 & 15,272 & 69.4 \\
\hline \multirow{2}{*}{$\begin{array}{l}\text { Motorcycle- } \\
\text { related injuries }\end{array}$} & Younger & 22,996 & 66.4 & 23,649 & 68.2 & 23,918 & 68.8 & 70,563 & 67.8 \\
\hline & Elderly & 5454 & 78.0 & 6053 & 82.3 & 5785 & 75.6 & 17,292 & 78.6 \\
\hline
\end{tabular}

Elderly, $\geq 65$ years old

Younger, $20 \sim 64$ years old

2016 to 2018. While bicycle-related injuries decreased among younger riders, motorcycle-related injuries increased. The number of elderly riders with two-wheeled vehicle-related injuries increased.

\section{Demographic characteristics of patients who visited EDs with two-wheeled vehicle related injuries (Table 2)}

There were 65,648 bicycle-related injuries $(50,376$ younger and 15,272 elderly riders). There were 35,906 (71.3\%) males among the younger riders and 12,406 (81.2\%) males among the elderly riders $(p<0.001)$. The analysis of the means of visit showed that younger bicyclists presented themselves to the ED, whereas elderly riders were usually transported by 911 emergency services. Younger bicycle riders wore helmets $(29.9 \%)$ more than elderly riders $(10.5 \%)(p<0.001)$. The incidence of bicycle accidents per 100,000 population was 69.4 in the elderly group (72.3 in urban, 64.6 in rural). This was higher than the incidence of 48.4 in the younger group which had more frequent accidents in urban areas $(p<0.001)$. There were more patients with altered consciousness in the elderly group than in the younger group $(p<0.001)$.

There were 87,855 motorcycle-related injuries (70,563 younger and 17,292 elderly riders). Male represented the majority among both younger (90.9\%) and elderly $(81.2 \%)$ riders $(p=0.001)$. Helmet use was more prevalent among younger riders $(80.7 \%)$ than among elderly riders $(62.4 \%) \quad(p<0.001)$. The incidence of motorcycle accidents per 100,000 population was 78.6 in the elderly group (54.8 urban, 118.1 rural), which was higher than the incidence in the younger group (67.8) $(p<0.001)$. Altered consciousness was more common in the elderly riders $(9.5 \%)$ than in younger riders $(4.2 \%)(p=0.001)$.
Injury patterns and clinical outcomes of patients who visited EDs with two-wheeled vehicle-related injuries (Table 3)

Bicycle-related injuries mainly involved the external body surface. The second most frequently injured area being the upper extremities in younger riders and the head and neck in elderly riders. Younger riders tended to break their forearm and clavicle, whereas elderly riders broke their forearm and femur. The average ISS was 7.1 \pm 8.9 for younger riders and $10.5 \pm 12.3$ for elderly riders $(p=0.001)$. The percentage of ISS $\geq 16$ points was higher in the elderly group than in the younger group $(22.7 \%$ vs $12.5 \%, p=0.001)$. The majority of younger riders $(77.6 \%)$ were discharged from the ED, $16.8 \%$ were admitted to the GW, and $2.4 \%$ were admitted to the ICU. In contrast, $57.2 \%$ of elderly riders were discharged from the ED, whereas $29.3 \%$ were admitted to the GW and $7.7 \%$ to the ICU. The mortality rate of elderly riders was higher than that of younger riders $(0.9 \%$ vs $0.2 \%)$.

Among patients with motorcycle-related injuries, younger riders mainly injured their external body surface and lower extremities, whereas elderly riders mainly injured their external body surface and head and neck areas. Younger riders mainly broke their forearm and spine, whereas elderly riders mainly broke their ribs or sternum and facial bones. The average ISS of the younger group was $9.8 \pm 11.2$ and that of the elderly group was $14.1 \pm 14.7(p=0.001)$. The percentage of ISS $\geq 16$ points was higher in the elderly group than in the younger group $(33.2 \%$ vs $20.9 \%)(p=0.001)$. Among younger riders, $68.8 \%$ were discharged, $20.9 \%$ were admitted to the GW, $4.1 \%$ were admitted to the ICU, and $0.8 \%$ died. Fewer elderly riders (39.6\%) were discharged, whereas $36.4 \%$ were admitted to the GW, $14.3 \%$ were admitted to the ICU, and $1.8 \%$ died. 
Table 2 Demographic characteristics of patients who visited the emergency department with two-wheeled vehicle-related injuries

\begin{tabular}{|c|c|c|c|c|c|c|c|c|}
\hline \multirow[t]{2}{*}{ Variable } & \multicolumn{4}{|l|}{ Bicycle } & \multicolumn{4}{|l|}{ Motorcycle } \\
\hline & Younger & Elderly & Total & p-value & Younger & Elderly & Total & $p$-value \\
\hline Number of injury cases & 50,376 & 15,272 & 65,648 & & 70,563 & 17,292 & 87,855 & \\
\hline Age & $43.3 \pm 13.3$ & $73.7 \pm 6.1$ & $50.4 \pm 17.6$ & 0.0001 & $37.4 \pm 13.1$ & $74.3 \pm 5.9$ & $44.7 \pm 19.0$ & 0.001 \\
\hline Number of males (\%) & $\begin{array}{l}35,906 \\
(71.3 \%)\end{array}$ & $\begin{array}{l}12,406 \\
(81.2 \%)\end{array}$ & $\begin{array}{l}48,312 \\
(73.6 \%)\end{array}$ & 0.0001 & $\begin{array}{l}64,112 \\
(90.9 \%)\end{array}$ & $\begin{array}{l}14,196 \\
(82.1 \%)\end{array}$ & $\begin{array}{l}78,308 \\
(89.1 \%)\end{array}$ & 0.001 \\
\hline Season of injury & & & & 0.0001 & & & & 0.001 \\
\hline Spring & $\begin{array}{l}13,702 \\
(27.2 \%)\end{array}$ & $3838(25.1 \%)$ & $\begin{array}{l}17,540 \\
(26.7 \%)\end{array}$ & & $\begin{array}{l}16,846 \\
(23.9 \%)\end{array}$ & $4505(26.1 \%)$ & $\begin{array}{l}21,351 \\
(24.3 \%)\end{array}$ & \\
\hline Summer & $\begin{array}{l}17,031 \\
(33.8 \%)\end{array}$ & $4564(29.9 \%)$ & $\begin{array}{l}21,595 \\
(32.9 \%)\end{array}$ & & $\begin{array}{l}20,024 \\
(28.4 \%)\end{array}$ & $5037(29.1 \%)$ & $\begin{array}{l}25,061 \\
(28.5 \%)\end{array}$ & \\
\hline Autumn & $\begin{array}{l}14,690 \\
(29.2 \%)\end{array}$ & $4582(30.0 \%)$ & $\begin{array}{l}19,272 \\
(29.4 \%)\end{array}$ & & $\begin{array}{l}19,796 \\
(28.1 \%)\end{array}$ & $4902(28.3 \%)$ & $\begin{array}{l}24,698 \\
(28.1 \%)\end{array}$ & \\
\hline Winter & $4.953(9.8 \%)$ & $2288(15.0 \%)$ & 7241 (11.0\%) & & $\begin{array}{l}13,897 \\
(19.7 \%)\end{array}$ & $2848(16.5 \%)$ & $\begin{array}{l}16,745 \\
(19.1 \%)\end{array}$ & \\
\hline Time of injury & & & & 0.0001 & & & & 0.001 \\
\hline Morning & $\begin{array}{l}10,698 \\
(21.2 \%)\end{array}$ & 4711 (30.8\%) & $\begin{array}{l}15,409 \\
(23.5 \%)\end{array}$ & & $\begin{array}{l}10,441 \\
(14.8 \%)\end{array}$ & $4945(28.6 \%)$ & $\begin{array}{l}15,386 \\
(17.5 \%)\end{array}$ & \\
\hline Afternoon & $\begin{array}{l}15,982 \\
(31.7 \%)\end{array}$ & $6427(42.1 \%)$ & $\begin{array}{l}22,409 \\
(34.1 \%)\end{array}$ & & $\begin{array}{l}22,068 \\
(31.3 \%)\end{array}$ & $7941(45.9 \%)$ & $\begin{array}{l}30,009 \\
(34.2 \%)\end{array}$ & \\
\hline Night & $\begin{array}{l}19,111 \\
(37.9 \%)\end{array}$ & 3677 (24.1\%) & $\begin{array}{l}22,788 \\
(34.7 \%)\end{array}$ & & $\begin{array}{l}29,356 \\
(41.6 \%)\end{array}$ & $3995(23.1 \%)$ & $\begin{array}{l}33,351 \\
(38.0 \%)\end{array}$ & \\
\hline Dawn & 4585 (9.1\%) & $457(3.0 \%)$ & $5042(7.7 \%)$ & & $8698(12.3 \%)$ & $411(2.4 \%)$ & 9109 (10.4\%) & \\
\hline Helmet use & & & & 0.0001 & & & & 0.001 \\
\hline Yes & $\begin{array}{l}15,062 \\
(29.9 \%)\end{array}$ & $1604(10.5 \%)$ & $\begin{array}{l}16,666 \\
(25.4 \%)\end{array}$ & & $\begin{array}{l}56,944 \\
(80.7 \%)\end{array}$ & $\begin{array}{l}10,790 \\
(62.4 \%)\end{array}$ & $\begin{array}{l}67,734 \\
(77.1 \%)\end{array}$ & \\
\hline No & $\begin{array}{l}35,314 \\
(70.1 \%)\end{array}$ & $\begin{array}{l}13,668 \\
(89.5 \%)\end{array}$ & $\begin{array}{l}48,982 \\
(74.6 \%)\end{array}$ & & $\begin{array}{l}13,619 \\
(19.3 \%)\end{array}$ & $6502(37.6 \%)$ & $\begin{array}{l}20,121 \\
(22.9 \%)\end{array}$ & \\
\hline Insurance type & & & & 0.0001 & & & & 0.001 \\
\hline National health care & $\begin{array}{l}33,295 \\
(66.1 \%)\end{array}$ & 7028 (46.0\%) & $\begin{array}{l}40,323 \\
(61.4 \%)\end{array}$ & & $\begin{array}{l}15,972 \\
(22.6 \%)\end{array}$ & $5671(32.8 \%)$ & $\begin{array}{l}21,643 \\
(24.6 \%)\end{array}$ & \\
\hline Traffic accident insurance & $\begin{array}{l}14,623 \\
(29.0 \%)\end{array}$ & $7415(48.6 \%)$ & $\begin{array}{l}22,038 \\
(33.6 \%)\end{array}$ & & $\begin{array}{l}50,164 \\
(71.1 \%)\end{array}$ & $\begin{array}{l}10,434 \\
(60.3 \%)\end{array}$ & $60,598(69.0)$ & \\
\hline Industrial accident insurance & $34(0.1 \%)$ & $6(0.0 \%)$ & $40(0.1 \%)$ & & $319(0.5 \%)$ & $17(0.1 \%)$ & $336(0.4 \%)$ & \\
\hline Medicaid & $1320(2.6 \%)$ & $587(3.8 \%)$ & 1907 (2.9\%) & & $1220(1.7 \%)$ & $564(3.3 \%)$ & $1784(2.0 \%)$ & \\
\hline Others & $1104(2.2 \%)$ & $236(1.5 \%)$ & $1340(2.0 \%)$ & & $2888(4.1 \%)$ & $606(3.5 \%)$ & $3494(4.0 \%)$ & \\
\hline Means of visit & & & & 0.0001 & & & & 0.001 \\
\hline 911 & $\begin{array}{l}20,638 \\
(41.0 \%)\end{array}$ & $8448(55.3 \%)$ & $\begin{array}{l}29,086 \\
(44.3 \%)\end{array}$ & & $\begin{array}{l}43,109 \\
(61.1 \%)\end{array}$ & $\begin{array}{l}10,374 \\
(60.0 \%)\end{array}$ & $\begin{array}{l}53,483 \\
(60.9 \%)\end{array}$ & \\
\hline Hospital ambulance & 1676 (3.3\%) & $1268(8.3 \%)$ & $2944(4.5 \%)$ & & 3447 (4.9\%) & $2842(16.4 \%)$ & $6289(7.2 \%)$ & \\
\hline Patient visit & $\begin{array}{l}27,920 \\
(55.4 \%)\end{array}$ & $5486(35.9 \%)$ & $\begin{array}{l}33,406 \\
(50.9 \%)\end{array}$ & & $\begin{array}{l}23,733 \\
(33.6 \%)\end{array}$ & $3911(22.6 \%)$ & $\begin{array}{l}27,644 \\
(31.5 \%)\end{array}$ & \\
\hline Others & $142(0.3 \%)$ & $70(0.5 \%)$ & $212(0.3 \%)$ & & $274(0.4 \%)$ & $165(1.0 \%)$ & $439(0.5 \%)$ & \\
\hline Area & & & & 0.0001 & & & & 0.001 \\
\hline Urban area & $\begin{array}{l}37,694 \\
(74.8 \%)\end{array}$ & $9928(65.0 \%)$ & $\begin{array}{l}47,622 \\
(72.5 \%)\end{array}$ & & $\begin{array}{l}51,316 \\
(72.7 \%)\end{array}$ & $7524(43.5 \%)$ & $\begin{array}{l}58,840 \\
(67.0 \%)\end{array}$ & \\
\hline $\begin{array}{l}\text { Number of urban injuries } 1100,000 \\
\text { population }\end{array}$ & 50.9 & 72.3 & 54.3 & & 69.3 & 54.8 & 67.0 & \\
\hline Rural area & $\begin{array}{l}12,682 \\
(25.2 \%)\end{array}$ & $5344(35.0 \%)$ & $\begin{array}{l}18,026 \\
(27.5 \%)\end{array}$ & & $\begin{array}{l}19,247 \\
(27.3 \%)\end{array}$ & $9768(56.5 \%)$ & $\begin{array}{l}29,015 \\
(33.0 \%)\end{array}$ & \\
\hline $\begin{array}{l}\text { Number of rural injuries } / 100,000 \\
\text { population }\end{array}$ & 42.2 & 64.6 & 47.1 & & 64.1 & 118.1 & 75.7 & \\
\hline
\end{tabular}


Table 2 Demographic characteristics of patients who visited the emergency department with two-wheeled vehicle-related injuries (Continued)

\begin{tabular}{|c|c|c|c|c|c|c|c|c|}
\hline \multirow[t]{2}{*}{ Variable } & \multicolumn{4}{|l|}{ Bicycle } & \multicolumn{4}{|l|}{ Motorcycle } \\
\hline & Younger & Elderly & Total & $p$-value & Younger & Elderly & Total & $p$-value \\
\hline Consciousness & & & & 0.0001 & & & & 0.001 \\
\hline Alert & $\begin{array}{l}49,487 \\
(98.2 \%)\end{array}$ & $\begin{array}{l}14,417 \\
(94.4 \%)\end{array}$ & $\begin{array}{l}63,904 \\
(97.4 \%)\end{array}$ & & $\begin{array}{l}67,615 \\
(95.8 \%)\end{array}$ & $\begin{array}{l}15,649 \\
(90.5 \%)\end{array}$ & $\begin{array}{l}83,264 \\
(94.8 \%)\end{array}$ & \\
\hline Altered & $884(1.8 \%)$ & $852(5.6 \%)$ & $1736(2.6 \%)$ & & $2944(4.2 \%)$ & $1641(9.5 \%)$ & $4585(5.2 \%)$ & \\
\hline Systolic blood pressure $(\mathrm{mmHg})$ & $133.4 \pm 26.8$ & $142.6 \pm 31.6$ & $135.6 \pm 28.2$ & 0.0001 & $134.4 \pm 29.6$ & $140.4 \pm 34.8$ & $135.6 \pm 30.8$ & 0.001 \\
\hline Diastolic blood pressure $(\mathrm{mmHg})$ & $81.4 \pm 21.3$ & $81.76 \pm 20.9$ & $81.4 \pm 21.2$ & 0.109 & $81.6 \pm 21.4$ & $80.8 \pm 23.0$ & $81.4 \pm 21.7$ & 0.001 \\
\hline Pulse rate (beats/min) & $82.0 \pm 21.0$ & $79.7 \pm 21.0$ & $81.4 \pm 20.8$ & 0.0001 & $83.4 \pm 20.6$ & $80.2 \pm 22.2$ & $82.8 \pm 21.0$ & 0.001 \\
\hline Respirate rate (/min) & $19.37 \pm 6.6$ & $19.3 \pm 4.1$ & $19.4 \pm 6.0$ & 0.606 & $19.3 \pm 13.7$ & $19.3 \pm 15.4$ & $19.3 \pm 4.1$ & 0.622 \\
\hline Body temperature $\left({ }^{\circ} \mathrm{C}\right)$ & $36.5 \pm 2.6$ & $36.6 \pm 3.5$ & $36.4 \pm 2.8$ & 0.0001 & $36.2 \pm 4.1$ & $36.1 \pm 4.3$ & $36.2 \pm 4.2$ & 0.009 \\
\hline
\end{tabular}

Elderly, $\geq 65$ years old

Younger, $20 \sim 64$ years old

Injury patterns and clinical outcomes of patients who were hospitalised with two-wheeled vehicle-related injuries (Table 4)

Among patients hospitalised for bicycle-related injuries, younger riders tended to injure their head and neck, external body surface, and upper extremities. Elderly riders mainly injured their head and neck, followed by their external body surface and lower extremities. A comparison of the fracture sites revealed that both groups suffered mainly spine injuries, followed by facial bone and rib and sternum fractures for the younger group, and rib and sternum and femur fractures for the elderly group. The average ISS was higher for elderly riders than for younger ones $(19.2 \pm 16.4$ vs $16.3 \pm 15.0) \quad(p=0.001)$, and more elderly riders (17\%) had more severe injuries (a higher percentage of ISS $\geq 16$ points) than younger riders $(7.4 \%)(p=0.001)$. The length of stay (LOS) in hospital was $485.2 \pm 543.0 \mathrm{~h}$ for elderly riders, which was longer than that of younger riders $(336.8 \pm 385.5 \mathrm{~h})$. The in-hospital mortality of elderly riders was more than three times that of younger riders (4.1\% vs $1.2 \%)$ $(p=0.001)$.

Among admitted patients, motorcyclists suffered more injuries than cyclists. Younger motorcyclists injured their lower extremities and head and neck, whereas elderly motorcyclists mainly injured their head and neck and chest. Younger patients were prone to fracturing their spine and facial bones, whereas elderly patients tended to fracture their ribs and sternum as well as their spine. The average ISS was $19.1 \pm 16.4$ for younger riders and $21.6 \pm 17.8$ for elderly riders $(p=0.001)$. The percentage of ISS $\geq 16$ points was $26.8 \%$ for the elderly group and $12.5 \%$ for the younger group $(p=0.001)$. Admitted motorcyclists stayed longer in the hospital than admitted bicyclists. The LOS in hospital was $452.0 \pm$ $543.6 \mathrm{~h}$ for younger motorcyclists and $529.6 \pm 598.6 \mathrm{~h}$ the elderly motorcyclists $(p=0.001)$. The in-hospital mortality rate was $1.7 \%$ the younger motorcyclists and $3.8 \%$ for the elderly motorcyclists $(p=0.001)$.

Factors predicting severe trauma (ISS $\geq 16$ ) in bicycle- and motorcycle-related injuries (Table 5)

The multivariable logistic regression analysis showed that the elderly group and rural areas were independent factors associated with severe trauma (ISS $\geq 16$ ). The elderly group had an adjusted odds ratio (OR) of 2.185 (95\% CI 2.072-2.303) for bicycle-related injuries and an adjusted OR of $1.220 \quad(95 \%$ CI $1.137-1.287)$ for motorcycle-related injuries compared to the younger group.

In the bicycle-related injury group, the rural area factor had an adjusted OR of 1.078 (CI 1.021-1.140) compared to the urban area.

\section{Discussion}

This was the first nationwide study to analyse the incidence and characteristics of two-wheeled vehicle-related injuries. This study is more representative than previous studies because it involved all regional emergency medical centres, local emergency medical centres, and local emergency medical rooms in South Korea. With increasing elderly population, South Korea is an ageing society; therefore, comparing such differences between the young and the elderly is very meaningful. When humans age, their brains shrink, including areas related to physical activity [25, 26]. Older people are more susceptible to two-wheeled accident-related injuries because they find it difficult to keep their balance and can fall easily owing to slowed reflexes. Senile degeneration causes serious medical problems and is a major factor that amplifies damage in the elderly by accelerating the decline in cognitive and motor skills due to physiological aging [27]. As life expectancy increases, injuries in the elderly 
Table 3 Injury patterns and clinical outcomes of patients who visited the emergency department with two-wheeled vehicle-related injuries

\begin{tabular}{|c|c|c|c|c|c|c|c|c|c|c|c|c|c|c|}
\hline \multirow[t]{2}{*}{ Variable } & \multicolumn{7}{|l|}{ Bicycle } & \multicolumn{7}{|c|}{ Motorcycle } \\
\hline & \multicolumn{2}{|c|}{ Younger } & \multicolumn{2}{|l|}{ Elderly } & \multicolumn{2}{|l|}{ Total } & \multirow[t]{2}{*}{$p$-value } & \multicolumn{2}{|c|}{ Younger } & \multicolumn{2}{|l|}{ Elderly } & \multicolumn{2}{|l|}{ Total } & \multirow[t]{2}{*}{$p$-value } \\
\hline Number of patients & 50,376 & & 15,272 & & 65,648 & & & 70,563 & & 17,292 & & 87,855 & & \\
\hline \multicolumn{15}{|l|}{ Injury pattern } \\
\hline \multicolumn{15}{|l|}{ Region of injury } \\
\hline Head and neck & 11,178 & $22.2 \%$ & 5927 & $38.8 \%$ & 17,105 & $26.1 \%$ & & 20,099 & $28.5 \%$ & 8931 & $51.6 \%$ & 29,030 & $33.0 \%$ & \\
\hline Face & 5153 & $10.2 \%$ & 1397 & $9.1 \%$ & 6550 & $10.0 \%$ & & 6062 & $8.6 \%$ & 2364 & $13.7 \%$ & 8426 & $9.6 \%$ & \\
\hline Chest & 5786 & $11.5 \%$ & 2782 & $18.2 \%$ & 8568 & $13.1 \%$ & & 11,607 & $16.4 \%$ & 5044 & $29.2 \%$ & 16,651 & $19.0 \%$ & \\
\hline $\begin{array}{l}\text { Abdomen and pelvic } \\
\text { contents }\end{array}$ & 438 & $0.9 \%$ & 178 & $1.2 \%$ & 616 & $0.9 \%$ & & 1559 & $2.2 \%$ & 479 & $2.8 \%$ & 2038 & $2.3 \%$ & \\
\hline External & 35,174 & $69.8 \%$ & 9592 & $62.8 \%$ & 44,766 & $68.2 \%$ & & 50,788 & $72.0 \%$ & 11,110 & $64.2 \%$ & 61,898 & $70.5 \%$ & \\
\hline pelvic girdle & 361 & $0.7 \%$ & 302 & $2.0 \%$ & 663 & $1.0 \%$ & & 968 & $1.4 \%$ & 386 & $2.2 \%$ & 1354 & $1.5 \%$ & \\
\hline Upper extremities & 17,342 & $34.4 \%$ & 3316 & $21.7 \%$ & 20,658 & $31.5 \%$ & & 22,452 & $31.8 \%$ & 4832 & $27.9 \%$ & 27,284 & $31.1 \%$ & \\
\hline Lower extremities & 11,471 & $22.8 \%$ & 3962 & $25.9 \%$ & 15,433 & $23.5 \%$ & & 32,737 & $46.4 \%$ & 5673 & $32.8 \%$ & 38,410 & $43.7 \%$ & \\
\hline Spine & 2546 & $5.1 \%$ & 1345 & $8.8 \%$ & 3891 & $5.9 \%$ & & 5185 & $7.3 \%$ & 1209 & $7.0 \%$ & 6394 & $7.3 \%$ & \\
\hline Number of fractures & 28,025 & & 9331 & & 37,356 & & & 45,524 & & 14,894 & & 60,418 & & \\
\hline \multicolumn{15}{|l|}{ Fracture site } \\
\hline Skull & 950 & $3.4 \%$ & 504 & $5.4 \%$ & 1454 & $3.9 \%$ & & 1910 & $4.2 \%$ & 955 & $6.4 \%$ & 2865 & $4.7 \%$ & \\
\hline Face & 4405 & $15.7 \%$ & 1275 & $13.7 \%$ & 5680 & $15.2 \%$ & & 5518 & $12.1 \%$ & 2210 & $14.8 \%$ & 7728 & $12.8 \%$ & \\
\hline Spine & 3366 & $12.0 \%$ & 1556 & $16.7 \%$ & 4922 & $13.2 \%$ & & 6665 & $14.6 \%$ & 1784 & $12.0 \%$ & 8449 & $14.0 \%$ & \\
\hline Rib, sternum & 2369 & $8.5 \%$ & 1334 & $14.3 \%$ & 3703 & $9.9 \%$ & & 4840 & $10.6 \%$ & 2834 & $19.0 \%$ & 7674 & $12.7 \%$ & \\
\hline Scapula & 1433 & $5.1 \%$ & 369 & $4.0 \%$ & 1802 & $4.8 \%$ & & 1831 & $4.0 \%$ & 690 & $4.6 \%$ & 2521 & $4.2 \%$ & \\
\hline Clavicle & 2725 & $9.7 \%$ & 357 & $3.8 \%$ & 3082 & $8.3 \%$ & & 2616 & $5.7 \%$ & 776 & $5.2 \%$ & 3392 & $5.6 \%$ & \\
\hline Humerus & 797 & $2.8 \%$ & 220 & $2.4 \%$ & 1017 & $2.7 \%$ & & 884 & $1.9 \%$ & 293 & $2.0 \%$ & 1177 & $1.9 \%$ & \\
\hline Forearm & 7605 & $27.1 \%$ & 1406 & $15.1 \%$ & 9011 & $24.1 \%$ & & 9691 & $21.3 \%$ & 1781 & $12.0 \%$ & 11,472 & $19.0 \%$ & \\
\hline Hand & 1724 & $6.2 \%$ & 293 & $3.1 \%$ & 2017 & $5.4 \%$ & & 2260 & $5.0 \%$ & 527 & $3.5 \%$ & 2787 & $4.6 \%$ & \\
\hline Pelvic ring & 256 & $0.9 \%$ & 233 & $2.5 \%$ & 489 & $1.3 \%$ & & 598 & $1.3 \%$ & 274 & $1.8 \%$ & 872 & $1.4 \%$ & \\
\hline Acetabulum & 72 & $0.3 \%$ & 58 & $0.6 \%$ & 130 & $0.3 \%$ & & 266 & $0.6 \%$ & 99 & $0.7 \%$ & 365 & $0.6 \%$ & \\
\hline Femur & 817 & $2.9 \%$ & 1034 & $11.1 \%$ & 1851 & $5.0 \%$ & & 1764 & $3.9 \%$ & 768 & $5.2 \%$ & 2532 & $4.2 \%$ & \\
\hline Patellar & 3 & $0.0 \%$ & 1 & $0.0 \%$ & 4 & $0.0 \%$ & & 15 & $0.0 \%$ & 2 & $0.0 \%$ & 17 & $0.0 \%$ & \\
\hline Tibia/fibula & 1012 & $3.6 \%$ & 547 & $5.9 \%$ & 1559 & $4.2 \%$ & & 4437 & $9.7 \%$ & 1490 & $10.0 \%$ & 5927 & $9.8 \%$ & \\
\hline Foot & 491 & $1.8 \%$ & 144 & $1.5 \%$ & 635 & $1.7 \%$ & & 2229 & $4.9 \%$ & 411 & $2.8 \%$ & 2640 & $4.4 \%$ & \\
\hline ISS & $\begin{array}{l}7.1 \pm \\
8.9\end{array}$ & & $\begin{array}{l}10.5 \pm \\
12.3\end{array}$ & & $\begin{array}{l}7.9 \pm \\
9.9\end{array}$ & & 0.001 & $\begin{array}{l}9.8 \pm \\
11.2\end{array}$ & & $\begin{array}{l}14.1 \pm \\
14.7\end{array}$ & & $\begin{array}{l}10.6 \pm \\
12.1\end{array}$ & & 0.001 \\
\hline ISS $\geq 16$ & 6297 & $12.5 \%$ & 3467 & $22.7 \%$ & 9764 & $14.8 \%$ & 0.001 & 14,747 & $20.9 \%$ & 5741 & $33.2 \%$ & 20,488 & $23.2 \%$ & 0.001 \\
\hline \multicolumn{15}{|l|}{ ED disposition } \\
\hline Discharge & 39,093 & $77.6 \%$ & 8734 & $57.2 \%$ & 47,827 & $72.9 \%$ & & 48,527 & $68.8 \%$ & 6850 & $39.6 \%$ & 55,377 & $63.0 \%$ & \\
\hline Transfer & 1365 & $2.7 \%$ & 715 & $4.7 \%$ & 2080 & $3.2 \%$ & & 2874 & $4.1 \%$ & 1326 & $7.7 \%$ & 4200 & $4.8 \%$ & \\
\hline ICU admission & 1234 & $2.4 \%$ & 1177 & $7.7 \%$ & 2411 & $3.7 \%$ & & 3675 & $5.2 \%$ & 2480 & $14.3 \%$ & 6155 & $7.0 \%$ & \\
\hline GW admission & 8449 & $16.8 \%$ & 4471 & $29.3 \%$ & 12,920 & $19.7 \%$ & & 14,738 & $20.9 \%$ & 6301 & $36.4 \%$ & 21,039 & $23.9 \%$ & \\
\hline Death & 82 & $0.2 \%$ & 143 & $0.9 \%$ & 225 & $0.3 \%$ & & 546 & $0.8 \%$ & 304 & $1.8 \%$ & 850 & $1.0 \%$ & \\
\hline Others & 129 & $0.3 \%$ & 26 & $0.2 \%$ & 155 & $0.2 \%$ & & 178 & $0.3 \%$ & 22 & $0.1 \%$ & 200 & $0.2 \%$ & \\
\hline
\end{tabular}

Elderly, $\geq 65$ years old

Younger, $20 \sim 64$ years old

$E D$ emergency department, GW general ward, ICU intensive care unit, ISS Injury severity score, LOS, Length of stay 


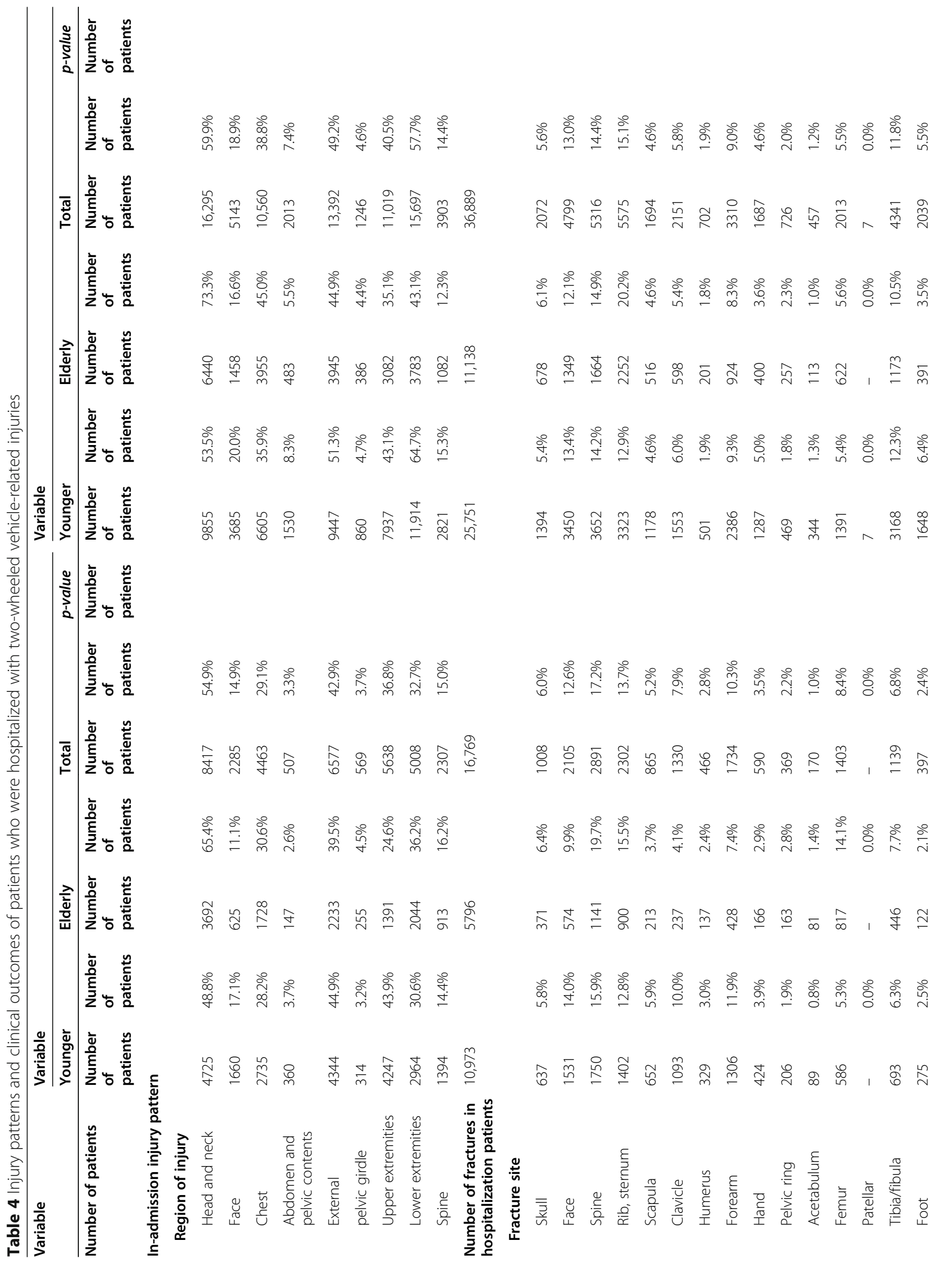




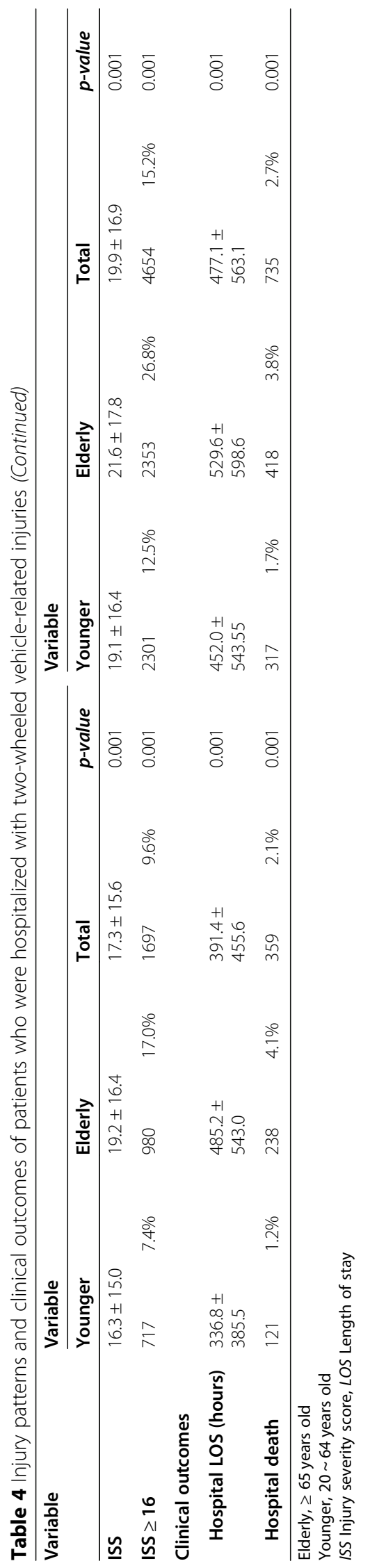


Table 5 Factors predicting severe trauma (ISS $\geq 16$ ) in bicycle- and motorcycle-related injuries

\begin{tabular}{|c|c|c|c|c|c|c|}
\hline \multirow[t]{2}{*}{ Outcome: ISS $\geq 16$} & \multicolumn{3}{|c|}{ Bicycle-related injury } & \multicolumn{3}{|c|}{ Motorcycle-related injury } \\
\hline & Adjusted OR & $95 \% \mathrm{Cl}$ & $p$-value & Adjusted OR & $95 \% \mathrm{Cl}$ & $p$-value \\
\hline \multicolumn{7}{|l|}{ Sex } \\
\hline Male & 1.007 & $0.949-1.067$ & 0.826 & 0.944 & $0.889-1.002$ & $0 . .057$ \\
\hline \multicolumn{7}{|l|}{ Age } \\
\hline Elderly & 2.185 & $2.072-2.303$ & 0.000 & 1.220 & $1.137-1.287$ & 0.003 \\
\hline \multicolumn{7}{|l|}{ Area } \\
\hline Rural & 1.078 & $1.021-1.140$ & 0.007 & 0.999 & $0.953-1.046$ & 0.959 \\
\hline \multicolumn{7}{|l|}{ Helmet use } \\
\hline No use & 1.000 & $0.941-1.064$ & 0.993 & 0.994 & $0.950-1.040$ & 0.794 \\
\hline \multicolumn{7}{|l|}{ Season } \\
\hline Spring & 1.000 & Reference & 0.730 & 1.000 & Reference & 0.046 \\
\hline Summer & 0.965 & $0.904-1.031$ & 0.291 & 1.007 & $0.956-1.060$ & 0.798 \\
\hline Autumn & 0.977 & $0.914-1.044$ & 0.489 & 1.058 & $1.006-1.114$ & 0.029 \\
\hline Winter & 0.995 & $0.911-1.087$ & 0.920 & 1.057 & $1.000-1.119$ & 0.051 \\
\hline \multicolumn{7}{|l|}{ Time } \\
\hline Morning (06:00 11:59) & 1.000 & Reference & 0.251 & 1.000 & Reference & 0.262 \\
\hline Afternoon (12:00 17:59) & 1.025 & $0.960-1.095$ & 0.460 & 1.031 & $0.977-1.088$ & 0.270 \\
\hline Night (18:00 23:59) & 0.992 & $0.927-1.062$ & 0.817 & 1.001 & $0.948-1.057$ & 0.961 \\
\hline Dawn (00:00 05:59) & 1.095 & $0.983-1.128$ & 0.099 & 1.056 & $0.981-1.137$ & 0.145 \\
\hline
\end{tabular}

and the resulting disabilities trigger a vicious cycle that causes additional medical problems by reducing the quality of life and physical activity [28].

Accident mortality from automobile accidents has declined in South Korea [29]. The increase in the survival rate has been attributed to the development of automobile technology, the expansion of road infrastructure, the improvement of emergency medical services, [30, 31] and the increase in the healthy elderly population [32]. The number of accidents has not decreased significantly. Indeed, the accident and mortality rates related to bicycles and motorcycles have been steadily increasing [18]. In this study, there were 584 deaths among 65,648 emergency visits due to bicycle-related injuries and 1585 deaths among 87,855 emergency visits due to motorcycle-related injuries over the three-year period.

Bicycles and motorcycles are popular vehicles worldwide. Riding a bicycle strengthens the muscles, increases physical activity, and promotes balance. In addition, bicycles are used as transportation because they are cheaper and easier to use than other means of transportation [33, 34]. The motorcycle is a convenient transportation mode, especially for travelling on roads that are difficult to access by car, and an enjoyable leisure activity for those who appreciate its speed.

Many studies have shown that wearing a helmet significantly reduces brain injury in the event of a twowheeler accident [35-37]. However, $74.6 \%$ of adult riders involved in bicycle accidents and $22.9 \%$ of riders involved in motorcycle accidents were not wearing a helmet. Tak reported that motorcycle helmets were used more by the elderly than by younger riders $(60.16 \%$ vs $51.87 \%$ ), whereas bicycle helmets was not used as much by the elderly $(2.37 \%$ vs. $4.82 \%)$ [38]. However, in this study, the rate of helmet use in the elderly group for both bicycle and motorcycle riders was lower than that of younger riders $(10.5 \%$ vs $29.9 \%$ for bicycle riders and $62.4 \%$ vs $80.7 \%$ for motorcycle riders) (Table 2). The analysis of patients visiting the ED revealed that more head and neck injuries occurred in motorcycle accidents than in bicycle accidents, which emphasises the importance of wearing a helmet when riding a motorcycle. In motorcycle accidents, helmet users showed a lower incidence, compared with those who did not wear a helmet, of head injury (mortality: $42 \%$ vs $69 \%$ ) [36] and neck injuries (mortality: $2.4 \%$ vs $7.1 \% ; p<0.01$ ) [39].

The elderly group showed fewer injuries during the night-time and dawn periods than younger riders in this study. This indicates that the lifestyles of elderly riders involved fewer outdoor activities at these times, which was consistent with the findings of a previous study that showed fewer traffic crashes caused by elderly riders than by younger riders during the same periods [40].

There was a high percentage of males associated with two-wheeled vehicular damage: $73.6 \%$ of bicyclists (71.3\% of younger riders, $81.2 \%$ of elderly riders) and 
$89.1 \%$ of motorcyclists (90.9\% of younger riders, $82.1 \%$ of elderly riders). Hsieh et al. reported that female motorcycle riders had different injury characteristics (lower ISS and in-hospital mortality) and presented with bodily injury patterns that differed from those of their male counterpats [41].

The incidence of two-wheeled vehicular accidents per million population was compared in urban and rural areas. There were usually more two-wheeled vehiclerelated adult trauma patients per 100,000 population in urban areas than in rural areas; however, there were more motorcycle-related trauma patients per 100,000 population in rural areas in the elderly group (54.8/ 100,000 population in urban areas and $118.1 / 100,000$ population in rural areas). This could be attributed to the greater suitability of motorcycles for rural roads and consequently wider use as the mode of transportation than cars. It is economically difficult to own a vehicle in the countryside. Many farm roads are narrow and unpaved, hindering vehicular access, and there is a lack of public transportation options in rural areas. Hence, motorcycles are often used in rural areas. The Korean population, especially the rural population, is ageing rapidly, with a large proportion of elderly people (aged $\geq 65$ years) in rural areas [42]. In 2019, the elderly accounted for $46.6 \%$ of the population involved in farming, 39.2\% in fishing, and $44.8 \%$ in forestry in rural areas [43]. Hence, policy efforts, such as the improvement of rural roads, the provision of safe and affordable alternative means of transportation, and the reinforcement of safety education for the elderly when using two-wheeled vehicles are necessary.

Among patients who visited the ED because of bicycle and motorcycle accidents, elderly riders mainly injured their head and neck and chest regions, which could be attributed to the lack of helmet use and poor agility. However, helmet use may not always prevent head injuries [44]. Injuries of the pelvis, upper extremities, and lower extremities were common in elderly riders. In bicycle-related accidents, younger riders usually injured their upper extremities, whereas elderly riders had more lower extremity injuries. Both younger and elderly riders fractured their forearm (27.1\% vs $15.1 \%)$, and fewer younger riders compared with elderly riders injured their lower extremities (3.6\% vs $5.9 \%$ tibia/fibula injuries and $2.9 \%$ vs $11.1 \%$ femoral injuries).

Fractures of the lower extremities were more common than those of the upper extremities in bicycle-related accidents, [36] and injuries of the pelvic region and extremities were the most common in elderly riders [45]. Liu et al. reported that cyclists had a higher rate of femoral injuries than motorcyclists [46]. Our study also showed more femoral fractures in bicycle-related accidents (5.0\%) than in motorcycle-related accidents (4.2\%).
This was due to femoral fractures in $11 \%$ of elderly riders with bicycle injuries compared to $2.9 \%$ in younger riders. However, in this study, in motorcycle accidents, the elderly group showed the most forearm fractures (12.0\%) and tibia/fibular fractures (10.0\%), which was consistent with the results reported by Chung et al. [45] While younger riders are thought to have more injuries to their upper extremities due to their faster response time and defensive use of their arms when falling from two-wheeled vehicles, the elderly are more likely to be crushed by the vehicle due to their slow response time. Therefore, injury patterns depend both on the mechanisms of the accident and the age of the riders [44]. Because elderly riders employ fewer defensive postures during falls, their injuries are more severe than those of younger riders. In the event of a two-wheeled vehiclerelated accident, the elderly have higher rates of ISS $\geq$ 16 , admission, and mortality than younger riders. Elderly motorcycle-related trauma patients had higher ISS, less favourable outcomes, a higher rate of admission to the ICU, and higher mortality than younger adult twowheeled vehicle riders. As motorcycles are faster and heavier than bicycles, riders suffer more injuries in motorcycle accidents.

Among the reasons for hospital admission through the ED, head and neck injuries were the leading cause (48.8\% for younger riders and $65.4 \%$ for elderly riders in bicycle accidents; $53.3 \%$ for younger riders and $73.3 \%$ for elderly riders in motorcycle accidents), while injuries to the extremities accounted for the largest proportion of patients who were hospitalised.

Among hospitalised patients, the most common sites of limb fractures in bicycle injuries were the forearm $(10.3 \%)$ and femur $(8.4 \%)$, and the most common sites of limb fractures in motorcycle injuries were the tibia/fibula (11.8\%) and forearm (9.0\%). Femoral fractures were almost three times more frequent in elderly bicyclists than in younger bicyclists. Elderly inpatients had higher ISS and mortality and longer hospital stays than younger riders involved in twowheeler accidents. Moreover, elderly patients with motorcycle-related injuries had more severe injuries and longer hospital stays than elderly bicycle-related trauma patients. Therefore, elderly riders suffered worse injuries and showed worse outcomes than younger riders in two-wheeled vehicular accidents. Two-wheeled vehicle-related trauma patients tend to develop fractures of the lower extremities as they age. Meessen et al. showed that the mortality rates of elderly riders after a proximal femoral fracture 1, 6, 12, and 24 months after the accident were 4.7, 16, 20.7, and $30.4 \%$, respectively [47]. Therefore, measures to reduce two-wheeled vehicle-related injuries should be considered from various angles for the growing 
elderly population. Attention should be paid not only to head and neck injuries, but also to lower extremity injuries in the ED.

From 2016 to 2018, the number of elderly involved in bicycle and motorcycle accidents increased, and the hospitalisation rate, mortality rate, and LOS in the hospital were all higher than those observed for younger riders.

South Korean society is predicted to become a superaged society, with the elderly accounting for more than $20 \%$ of the population by 2026 ; hence, two-wheeled vehicle-related injuries are expected to increase further among the elderly.

This study can serve as the basis for preparing a plan to reduce the incidence and severity of injuries in the elderly by analysing the characteristics of trauma.

However, this study has several limitations. It did not consider other factors that affect the rates of twowheeled vehicular accidents, such as weather, pavement, flow of traffic, roadworthiness of the two-wheeled vehicle, and medical costs [31, 32, 44]. Homma et al. suggested that alcohol consumption increased medical cost and independently affected injury severity [2]; however, alcohol consumption was not considered in this study.

This study did not investigate whether the purpose of the two-wheeled vehicles was for leisure, commuting, or work. A total of 4267 (2.0\%) patients were excluded because of the poor fidelity of the transferred data. This may have affected the results.

In this study of two-wheeled vehicle related injuries, the analysis of the entire population without access to the risk-exposed group was a limitation. According to data from the National Police Agency, [48] the elderly group held $37.7 \%$ of car licenses and $2.3 \%$ of motorcycle licenses, whereas the younger group held $77.1 \%$ of car licenses and $0.36 \%$ of motorcycle licenses. However, because a group with a license could not be viewed only as a risk group, each group had a license and might not operate. There could be many cases of people, not operating or owning a device. It was also because there was a possibility of a passenger injury.

Finally, re-admission or post-outpatient hospitalisation after discharge from the ED was not monitored.

\section{Conclusion}

Two-wheeled vehicle-related injuries in the elderly were associated with higher ISS, hospitalisation rates, length of hospital stay, and mortality than in younger riders. Helmet use was low among the elderly. Injuries to the head and lower extremities, especially femoral fractures, were more common in elderly bicyclists. Analysing the characteristics of injuries in the elderly related to two-wheeled vehicles-related accidents can be the basis for planning to reduce and prevent injuries in elderly riders.

\section{Acknowledgments}

We thank Hye Ah Lee, Ph.D., for helping with the statistical analysis. This study utilized the National Emergency Department Information System (NEDIS) data (N20200720511).

\section{Authors' contributions}

$\mathrm{DHL}$ performed the analysed the data authored and prepared the tables. JIL conceived and designed the research, performed the analysed the data, and authored and reviewed the drafts of the manuscript. YC wrote the manuscript draft. JIL and DHL contributed equally as corresponding authors. All authors approved the final draft.

\section{Funding}

This work was supported also by the National Research Foundation of Korea (NRF) grant funded by the Korea government (MSIT) (NRF-

2020R1C1C1004851) (J.I.L).

The funders had no role in study design, data collection and analysis, decision to publish, or preparation of the manuscript.

\section{Availability of data and materials}

The datasets used and/or analysed during the current study are available from the corresponding author on reasonable request.

\section{Declarations}

Ethics approval and consent to participate

This study was approved by the institutional review board (IRB) of Ewha Womans' University Mok-dong Hospital (IRB No. 2020-12-007) and was approved by the ethical principles of the Declaration of Helsinki. All methods were performed in accordance with the relevant guidelines and regulations. Informed consent was waived by the IRB because of the retrospective nature of the study; and patient information was anonymised before the analysis.

\section{Consent for publication}

NA

\section{Competing interests}

The authors declare that they have no competing interests.

Received: 16 April 2021 Accepted: 24 September 2021

Published online: 26 October 2021

\section{References}

1. Peden M, Scurfield R, Sleet D, Hyder AA, Mathers C, Jarawan E, et al. World report on road traffic injury prevention: World Health Organization; 2004. https://www.who.int/publications/i/item/world-report-on-road-traffic-injuryprevention

2. Homma Y, Yamauchi S, Mizobe M, Nakashima Y, Takahashi J, Funakoshi H, et al. Emergency department outpatient treatment of alcohol-intoxicated bicyclists increases the cost of medical care in Japan. PLoS One. 2017;12(3): e0174408. https://doi.org/10.1371/journal.pone.0174408.

3. Crocker P, King B, Cooper H, Milling T. Self-reported alcohol use is an independent risk factor for head and brain injury among cyclists but does not confound helmets' protective effect. J Emerg Med. 2012;43(2):244-50. https://doi.org/10.1016/j.jemermed.2011.05.029.

4. Hamer M, Chida Y. Active commuting and cardiovascular risk: a metaanalytic review. Prev Med. 2008;46(1):9-13. https://doi.org/10.1016/j.ypmed.2 007.03.006.

5. Pucher J, Buehler R. Safer cycling through improved infrastructure. Am Public Health Assoc. 2016;106(12):2089-91. https://doi.org/10.2105/AJPH.201 6.303507.

6. Shin SJ, Ryoo HW, Park JB, Seo KS, Jung JM, Park DC, et al. Characteristics and risk factors of bicycle injury. J Korean Soc Emerg Med. 2010;21(3):32834.

7. Kim SYBK. Direction for the improvement of legislation about bicycle utilization. Geograph J Korea. 2008;42(1):35-48. https://doi.org/10.25024/kj.2 008.48.4.35.

8. Legislation KMoG: Promotion of the use of bicycles act of 2009. Sejong; 2009. 
9. Number of bicycle lanes and total extension (year, 2009-2019) [http://www. index.go.kr/potal/stts/idxMain/selectPoSttsldxSearch.do?idx_cd=2854\&stts_ $c d=285401 \&$ freq=Y.] Accessed 6 Nov 2020.

10. Public bicycle operation status [http://kosis.kr/statHtml/statHtml.do?orgld= 110\&tblld=DT_110031_010\&conn_path=|2] Accessed 6 Nov 2020.

11. Bicycle use status as of 2018 [https://www.mois.go.kr/frt/bbs/type001/ commonSelectBoardArticle.do?bbsld=BBSMSTR_000000000014\&nttld=72681 ] Accessed 29 Dec 2020.

12. Traffic accident statistics analysis [ https://www.taas.koroad.or.kr/web/bdm/ srs/selectStaticalReportsList.do?menuld=WEB_KMP_IDA_SRS_TAA ] Accessed 1 Nov 2020.

13. Güngör F, Oktay C, Topaktaş Z, Akçimen M. Analysis of motorcycle accident victims presenting to the emergency department. Ulus Travma Acil Cerrahi Derg. 2009;15(4):390-5.

14. Lin M-R, Kraus JF. A review of risk factors and patterns of motorcycle injuries. Accid Anal Prev. 2009;41(4):710-22. https://doi.org/10.1016/j.aap.2 009.03.010.

15. Jama HH, Grzebieta RH, Friswell R, McIntosh AS. Characteristics of fatal motorcycle crashes into roadside safety barriers in Australia and New Zealand. Accid Anal Prev. 2011;43(3):652-60. https://doi.org/10.1016/j.aap.2 010.10 .008$.

16. Erdogan MO, Sogut O, Colak S, Ayhan H, Afacan MA, Satilmis D. Roles of motorcycle type and protective clothing in motorcycle crash injuries. Emerg Med Int. 2013;2013:1-4. https://doi.org/10.1155/2013/760205.

17. Vlahogianni El, Yannis G, Golias JC. Overview of critical risk factors in powertwo-wheeler safety. Accid Anal Prev. 2012;49:12-22. https://doi.org/10.1016/ j.aap.2012.04.009.

18. The Organization for Economic Co-operation and Development countries accident statistics [http://taas.koroad.or.kr/sta/acs/exs/typical.do?menuld= WEB_KMP_OVT_UAS_ONT] Accessed 6 Jan 2021.

19. Pai $\mathrm{CW}$, Lin $\mathrm{HY}, \bar{T}$ sai $\overline{\mathrm{SH}}$, Chen PL. Comparison of traffic-injury related hospitalisation between bicyclists and motorcyclists in Taiwan. PLoS One. 2018;13(1):e0191221. https://doi.org/10.1371/journal.pone.0191221.

20. Traffic accident trend [https://www.police.go.kr/www/open/publice/ publice2019_04.jsp] Accessed 6 Jan 2021.

21. Statistical yearbook of the National Emergency Department Information System [https://www.e-gen.or.kr/nemc/statistics_annual_report. do?brdclscd=02] Accessed 6 Jan 2021

22. Ikpeze TC, Glaun G, McCalla D, Elfar JC. Geriatric cyclists: assessing risks, safety, and benefits. Geriatr Orthop Surg Rehabil. 2018;9:2151458517748742. https://doi.org/10.1177/2151458517748742.

23. Statistical yearbook of emergency medical service [ https://www.e-gen.or.kr/ nemc/statistics_annual_report.do .] Accessed 6 Jan 2021.

24. Korean Standard Classification of Diseases, KCD [ https://kcdcode.kr/browse/ contents/0 ] Accessed 19 Jul 2020.

25. Colcombe SJ, Erickson KI, Scalf PE, Kim JS, Prakash R, McAuley E, et al. Aerobic exercise training increases brain volume in aging humans. J Gerontol A Biol Sci Med Sci. 2006;61(11):1166-70. https://doi.org/10.1093/ gerona/61.11.1166

26. Erickson Kl, Voss MW, Prakash RS, Basak C, Szabo A, Chaddock L, et al. Exercise training increases size of hippocampus and improves memory. Proc Natl Acad Sci U S A. 2011;108(7):3017-22. https://doi.org/10.1073/pnas.101 5950108.

27. Kim J-M, Lee M-S. Risk factors for falls in the elderly population in Korea: an analysis of the third Korea national health and nutrition examination survey data. Korean J Health Educ Promot. 2007;24(4):23-39.

28. Yang Y-M, Kim E-S. The status of incidence and the prognostic Factorsin geriatric trauma patients. J Korean Soc Traumatol. 2004;17(1):37-48.

29. Ahn JY, Ryoo HW, Park JB, Kim JK, Lee MJ, Lee DE, et al. Comparison of traffic collision victims between older and younger drivers in South Korea: epidemiologic characteristics, risk factors and types of collisions. PLoS One. 2019;14(4):e0214205. https://doi.org/10.1371/journal.pone.0214205.

30. Robertson LS. Prevention of motor-vehicle deaths by changing vehicle factors. Inj Prev. 2007;13(5):307-10. https://doi.org/10.1136/ip.2007.016204.

31. Goldman S, Siman-Tov M, Bahouth H, Kessel B, Klein Y, Michaelson M, et al. The contribution of the Israeli trauma system to the survival of road traffic casualties. Traffic Inj Prev. 2015;16(4):368-73. https://doi.org/10.1080/153 89588.2014.940458.

32. Hung WW, Ross JS, Boockvar KS, Siu AL. Recent trends in chronic disease, impairment and disability among older adults in the United States. BMC Geriatr. 2011;11(1):47. https://doi.org/10.1186/1471-2318-11-47.
33. De Geus B, Van Hoof E, Aerts I, Meeusen R. Cycling to work: influence on indexes of health in untrained men and women in Flanders. Coronary heart disease and quality of life. Scand J Med Sci Sports. 2008;18(4):498-510. https://doi.org/10.1111/j.1600-0838.2007.00729.x.

34. Matthews CE, Jurj AL, Shu XO, Li HL, Yang G, Li Q, et al. Influence of exercise, walking, cycling, and overall nonexercise physical activity on mortality in Chinese women. Am J Epidemiol. 2007;165(12):1343-50. https:// doi.org/10.1093/aje/kwm088.

35. Sethi M, Heidenberg J, Wall SP, Ayoung-Chee P, Slaughter D, Levine DA, et al. Bicycle helmets are highly protective against traumatic brain injury within a dense urban setting. Injury. 2015;46(12):2483-90. https://doi.org/1 0.1016/j.injury.2015.07.030.

36. Liu BC, Ivers R, Norton R, Boufous S, Blows S, Lo SK. Helmets for preventing injury in motorcycle riders. Cochrane Database Syst Rev. 2008;23(1): CD004333.

37. Hsieh CH, Liu HT, Hsu SY, Hsieh HY, Chen YC. Motorcycle-related hospitalizations of the elderly. Biom J. 2017;40(2):121-8. https://doi.org/10.1 016/j.bj.2016.10.006

38. Tak Y-J. Comparison of characteristics of risk behaviors and injuries between elderly and young population in Korea: application of convergence educational concept. J Digital Converg. 2015;13(5):289-96. https://doi.org/1 0.14400/JDC.2015.13.5.289.

39. Park GJ, Shin J, Kim SC, Na DS, Lee HJ, Kim H, et al. Protective effect of helmet use on cervical injury in motorcycle crashes: a case-control study. Injury. 2019;50(3):657-62. https://doi.org/10.1016/j.injury.2019.01.030.

40. McGwin G Jr, Brown DB. Characteristics of traffic crashes among young, middle-aged, and older drivers. Accid Anal Prev. 1999;31(3):181-98. https:// doi.org/10.1016/S0001-4575(98)00061-X.

41. Hsieh C-H, Hsu S-Y, Hsieh H-Y, Chen Y-C. Differences between the sexes in motorcycle-related injuries and fatalities at a Taiwanese level I trauma center. Biom J. 2017;40(2):113-20. https://doi.org/10.1016/j.bj.2016.10.005.

42. C-H YEO, Y-H SEO. An analysis on the spatial spillover patterns of aging population in rural area. J Korean Assoc Geograph Inf Stud. 2014;17(3):3953. https://doi.org/10.11108/kagis.2014.17.3.039.

43. 2019 Agricultural, Forestry and Fishery Survey Results [http://kostat.go.kr/ portal/korea/kor_nw/1/8/6/index.board?bmode=read\&aSeq=381656\&pa geNo=\&rowNum=10\&amSeq=\&sTarget=\&sTxt=] Accessed 2 Jan 2021.

44. Juhra C, Wieskoetter B, Chu K, Trost L, Weiss U, Messerschmidt M, et al. Bicycle accidents-do we only see the tip of the iceberg?: a prospective multi-Centre study in a large German city combining medical and police data. Injury. 2012;43(12):2026-34. https://doi.org/10.1016/j.injury.2011.10.016.

45. Cheong HS, Tham KY, Chiu LQ. Injury patterns in elderly cyclists and motorcyclists presenting to a tertiary trauma centre in Singapore. Singapore Med J. 2020. https://doi.org/10.11622/smedj.2020038.

46. Liu H-T, Rau C-S, Liang C-C, Wu S-C, Hsu S-Y, Hsieh H-Y, et al. Bicycle-related hospitalizations at a Taiwanese level I trauma center. BMC Public Health 2015;15(1):722. https://doi.org/10.1186/s12889-015-2075-9.

47. Meessen JMTA, Pisani S, Gambino ML, Bonarrigo D, Van Schoor NM, Fozzato $\mathrm{S}$, et al. Assessment of mortality risk in elderly patients after proximal femoral fracture. Orthopedics. 2014;37(2):e194-200. https://doi.org/10.3928/ 01477447-20140124-25.

48. 2018 Status of driver's license holders (by age) [https://kosis.kr/statHtml/sta tHtml.do?orgld=132\&tblld=DT_13201_A002\&conn_path=|3] Accessed 25 May 2021.

\section{Publisher's Note}

Springer Nature remains neutral with regard to jurisdictional claims in published maps and institutional affiliations. 